\title{
LXIV. Observations on the flexure of astronomical instruments
}

\section{Mr. Thomas Tredgold}

To cite this article: Mr. Thomas Tredgold (1822) LXIV. Observations on the flexure of astronomical instruments, Philosophical Magazine Series 1, 60:295, 338-340, DOI: 10.1080/14786442208652854

To link to this article: http://dx.doi.org/10.1080/14786442208652854

册 Published online: 29 Jul 2009.

Submit your article to this journal

Џ Article views: 2

Q View related articles $₫$ 
moon would have no centre to revolve about, and consequently would fly off in a tangent. The ticle on the opposite side to the moon is occasioned by the centrifugal force which necessarily arises from the revolution of the earth and moon round their common centre of gravity, on the same principle that the waters at the equator are elevated from the centre by the diumal revolution of the earth on its axis.

Captain Forman has made assertions in his postscript to which, of course, I cannot assent. I shall, however, notice a peculiar sort of convenience in which the Captain so freely indulges; namely, that of deciding without considering. He says," Mr. Russell, I suppose, is so much of a philosopher as to know that whenever it is low water in any place, the tides are rising on one side of it and ebbing on the other; and if the 'superior gravity' of the water in this place cannot prevent the waters from ebbing on one side, it is not very philosophical to suppose that it can lift the waters on the other." Captain Forman would have saved himself the trouble of this last assertion, if he had previously considered that the earth is continually turning on its axis; and consequently is in regular succession exposing every degree of the equator on one side to the centrifugal force, and on the other side to the attractive power of the moon; and as the most dense waters (the ebbs) necessarily form an isosceles triangle with the moon, so are they ever ready to buoy up the flows.

I now take leave of this controversy, and promise in some future number of your Magazine to lay before your readers some observations on the expansibility of water as connected with the rising of the ocean.

Henry Russeli.

LXIV. Observations on the Flexure of Astronomical Instruments. By Mr. Thomas 'Tredgold, Civil Engineer*.

$\mathbf{T}$ HE further improvement of the accuracy of astronomical observations being of great importance to the advancement of that science, a few remarks on the flexure of the parts of instruments may perhaps be regarded with interest by some of your readers.

A slight acquaintance with the properties of natural bodies must have informed even a careless observer, that no kind of matter is endowed with perfect inflexibility; and on a closer examination we find that every change in the position or points of support of a body, is accompanied by a corresponding change in its structure: the different parts of the body be-

* Communicated by the Author. 
come extended or compressed in a different degree, or that which was extended in the first position becomes compressed by the change, and the reverse. In many cases these changes may be made sensible to the eye, and their effects may be shown in all bodies, when their magnitude is sufficient for applying proper instruments.

From these principles, then, which experience furnishes, we may anticipate, that a change of form takes place in every new position of an instrument; and consequently that it should be so constructed as to render the effect of these changes of form insensible in making observations; or, where that cannot be accomplished, the effect of flexure should be estimated, and the observations corrected accordingly.

In the construction of instruments, it is therefore desirable to inquire what form is adapted for any given purpose; and, assuming that the flexure will have a sensible effect, it will be of some advantage that the form be of the simplest kind, at least as far as regards the calculation of its flexure.

And here we may remark, that ceconomy of material is of little if any importance, and therefore the forms of equal strength should be abandoned, and those of the least flexure substituted in their place. And since easy movement is not so essential as accurate movement, that form of axis seems the best which unites the greatest accuracy of form with that which is least flexible.

If an instrument be supported by a horizontal axis, and it be put in motion, the centre will rotate in a circle of which the radius is equal to the flexure of the axis at the point intersected by the plane of the graduated arc or circle.

Let us suppose the axis to be an uniform solid cylinder of which the radius is $r$, and the length from centre of pressure to centre of pressure $l, \mathrm{~W}$ the weight of the moveable part of the instrument, and $M$ the weight of the modulus of elasticity of the substance to a base of unity; also let $p$ be the circumference of a circle of which the radius is 1 or unity; then

$$
\frac{\mathrm{W} l 3}{12 \mathrm{l}^{3} \mathrm{M}}=\delta \text { or the deflexion in the middle*. (A). }
$$

If the axis be a tube or hollow cylinder of uniform diameter, and $r$ be the radius of the exterior part of the axis, and $n r$ be the radius of the hollow part; then

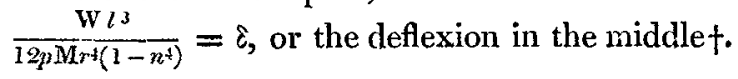

* Praetical Essay on Cast-Iron, \&c. artt. 81, 87, and 100. The expression $\frac{f}{\varepsilon}=\mathrm{M}$ in this notation. The same equation may be derived from artt. 326 and 339 B of Dr. Young's Natural Philosophy, vol. ii.

+ Pract. Essay on Iron, artt. 83, 87, and 100. 
If the axis be diminished from the point where the weight acts towards the points of support, so as to be of equal strength in every part, the figure of each semi-axis will be that generated by the revolution of a cubic parabola. In this case the deflexion is greater; being, when $r=$ the greatest diameter,

$$
\frac{3 \mathrm{~W} \iota^{3}}{20 p M r^{4}}=\delta^{*} \text {. }
$$

The same may be shown in the case of a hollow cylinder, and it may be proved generally that an uniform cylinder, whether solid or hollow, is stiffer than any figure inscribed within it.

When an axis is formed of cylinders of different diameters, the deflexion of the middle part will be $\frac{W\left(L^{3}-l^{3}\right)}{12 p \text { M } R^{4}}$, and the deflexion of the extremities $\frac{\mathrm{W} l 3}{12 p} \overline{\mathrm{M}} r^{2}$; consequently the whole deflexion will be $\frac{\mathrm{W}}{12 p} \times\left(\frac{\mathrm{L}^{3}-l^{3}}{\mathrm{MR}+}+\frac{\iota^{3}}{\mathrm{M} r^{4}}\right)=\delta$.

Where $L$ is the whole length, $l$ the sum of the lengths of the small cylinders, $\mathrm{R}$ the radius of the middle, and $r$ the radius of the small cylinders. If the two cylinders be of different metals, $M$ will differ in value in the different members of the equation.

[To be continued.]

\section{On Governor EuLus's Discovery of the Action of Cold on Magnetic Needles.}

To the Editors of the Philosophical Magazine and Journal.

Lansdown Crescent, Bath, Nov. 9, 1822. Genthemen, - A FEw days ago, in looking over your publication for last September, my attention was arrested by part of a letter from B. De Sanctis, M.D. " respecting some frigorific experiments made on the magnetic fluid." Their principal result is, - that at certain low temperatures magnetic needles lose their powers, which the writer attributes to the action of cold on the magnetic fluid. Neither the fact, however, nor the explanation is new. Above seventy years ago the fact was made known to the world, and a nearly similar explanation + of it given by $\mathrm{Mr}$. Ellis + in the account he pub-

* Essay on Cast-Iron, artt. 81, 90, and 100.

lished

+ The chief difference of the explanations is only this: Mr. Ellis conjectured that the action of cold on the ncedle, as well as on the magnetic particles or fluid, may contribute to produce the effect; while Dr. De Sanctis exciudes the action of cold on the needle from any share of the effect. "It is only, or at least principally," he says, " the action of cold on the magnetic fluid itself that produces the paralysis" of the needle; and he intimates that the magnetic fuid may be frozen into a refined ethereal ice!

$\ddagger$ The late Governor Henry Ellis, who died in 1803; and was, for se- 